\title{
Index for Volume 88 of Plant Disease
}

AUTHOR AND SUBJECT INDEX. Page numbers of errata are in italic. N indicates disease note. Publication no. D-2004-1011-010

Aanonsen, E., 224N

Abdoul-Karime, A. L., 681N

Abina, J., 1047N

Aceria tosichella, on wheat, High Plains virus vector, 824

Acharya, S. N., 1246

Achdari, G., 1284N

Acosta-Gallegos, J. A., 152

Acremonium implicatum, on Brachiaria grass, seed-transmitted endophyte, 1252

Adhikari, T., 4, 308

Adkins, S., 34, 674

Aegerter, B. J., 772N

Agathsoma betulina, root-knot nematode, South Africa, 574N

Agostini, J. P., 379

Agrobacterium sp., on weeping fig, tumorigenic, Spain, 428N

Agrostis stolonifera, dollar spot, Argentina, $1384 \mathrm{~N}$

Ahlawat, Y. S., 426N

Ahoonmanesh, A., 424N, 909N

Aime, M. C., $1161 \mathrm{~N}$

Akebia quinata, powdery mildew, Italy, $682 \mathrm{~N}$

Al Rwahnih, M., 1162N

Alderman, S. C., 63

Alexander, H. M., 574N

Alfalfa (see also Lucerne)

Alfalfa

_blossom blight, biocontrol factors, 1246

-brown root rot, in Wisconsin, $769 \mathrm{~N}$

-Verticillium wilt, factors and fungicides, yield, 811

Alfalfa mosaic virus, on Lavandula officinalis, Spain, 908N

Alfenas, A. C., 758

Alippi, A. M., $1381 \mathrm{~N}$

Alleyne, A. T., 830

Allium cepa, Tomato spotted wilt virus and Iris yellow spot virus, in Georgia, $1285 \mathrm{~N}$

Alternaria spp.: on carrot, feature, 776; on hazelnut and walnut, disease complexes, $426 \mathrm{~N}$

-A. alternata: on compass plant, stem blight, cover photo, October; on jujube fruit disease, postharvest, 497; on Silphium laciniatum, Poland, 1045N

-A. brassicae, on crucifer seed, PCR assay for detection, 490

-A. panax, on Aralia japonica, in Europe, $82 \mathrm{~N}$

$-A$. radicina, on carrot, cover photo, August

-A. solani: on potato, genetic diversity in South Africa, 959; sensitivity to $\mathrm{Q}_{\mathrm{o}} \mathrm{I}$ fungicides, 181

-A. tenuissima, on highbush cranberry, leaf spot, twig blight, fruit rot, Argentina, $1383 \mathrm{~N}$

Althaea officinalis, anthracnose, Italy, $425 \mathrm{~N}$

Alvarez, A. M., 1318

Alves, E., 453

Amaranthus hybridus

- stem decay and canker, Hypolixus haerens association, 333

-stem infections, cover photo, April

Amomum subulatum, nanovirus and foorkey disease, India, $428 \mathrm{~N}$

Anethum graveolens, powdery mildew, in Spain, $905 \mathrm{~N}$

Angui, P., 1047N

Anith, K. N., 669

Ann, P. J., 1383N

Anthriscus cerefolium, powdery mildew,

California, $1163 \mathrm{~N}$

Anwar, A., 680N
Aoki, T., 1044N

Apple

-blue mold: isolate characterization in Uruguay, 23; mechanical harvesting and biocontrol, 662

-Botryosphaeria spp., temperature effect on sporulation, 292

-fire blight: forecasting and biocontrol, 41; prohexadione-calcium dose level, 1099

- fruit infection, inoculum concentration and calcium salts, 147

-Glomerella leaf spot and bitter rot, population diversity in North Carolina, 1335

- scab: ascospore maturity and release, method comparison, 869; epidemics and conidial overwintering, 751

-Sphaeropsis pyriputrescens, postharvest fruit rot, $223 \mathrm{~N}$

Apple stem pitting virus, on pear, stony pit, cover photo, May

Aquilegia flabellata, powdery mildew, Italy, $681 \mathrm{~N}$

Arabis mosaic virus, on grape, Iran, 424N

Aralia japonica, Alternaria leaf blight, in Europe, $82 \mathrm{~N}$

Aranda, M. A., 907N

Araya, C. M., 830

Arbutus menziesii, Phytophthora ramorum and Botryosphaeria dothidea on, disease progression, 852

Arceuthobium vaginatum, on pine, Mexico, $1046 \mathrm{~N}$

Arelli, A. P., 721

Argyranthemum frutescens, powdery mildew, California, $1163 \mathrm{~N}$

Armengol, J., 84N

Armillaria mellea, on grape, postinfection control, 1235

Armstrong, J. W., 1318

Aroids, bacterial blight, detection methods, 980

Arroyo, F. T., 878

Arunyanart, P., 557

Asciutto, K., 86N

Ascochyta rabiei

-on chickpea, blight, cover photo, January

- genetic diversity, in Canada, 4, 308

Ash, anthracnose, Oregon, 222N

Aspergillus flavus, in soil and corncobs, management implication, Texas, 1366

Atallah, Z. K., 419

Attar, N., 424N

Auclair, J., 891

Auger, J., $1285 \mathrm{~N}, 1286 \mathrm{~N}$

Avila-Adame, C., 537

Ayres, A. J., 453

Aysan, Y., 310N, 907N

Azalea japonica, leaf spot, Italy, $572 \mathrm{~N}$

Babadoost, M., 56, 485

Bacteriocide, copper, pepper bacterial spot control, 921

Badillo-Ponce, G., 1283N

Baeyen, S., 427N

Baker, C. A., 223N

Balogh, B., 736

Banana

—black Sigatoka, Grand Bahama Island, $772 \mathrm{~N}$

-Fusarium wilt, resistance, somaclonal variation, Taiwan, 580

Barley

-Fusarium head blight: deoxynivalenol accumulation, 837; resistance, 167 -net blotch, spot type, Uruguay first report, $1162 \mathrm{~N}$

-yellow dwarf, tallgrass prairie, Kansas, 574N

Barley yellow striate mosaic virus, on wheat, in Syria, 83N

Barnes, J. E., 575N

Barnes, L., 1049N

Barrau, C., 878

Barrera, V., $86 \mathrm{~N}$

Barreto, D., 1384N

Barrios, H., 557

Barta, A., $1285 \mathrm{~N}$

Bash, J. A., 709, 1328

Basim, E., 85N, 1048N, 1050N

Basim, H., 85N, 1048N, 1050N

Bassanezi, R. B., 453

Bau, H.-J., 594

Baudry, A., 220N

Baumgartner, K., 1235

Bean common mosaic virus, on vanilla, French Polynesia, 119

Bean yellow mosaic virus, in Verbena hybrids, $574 \mathrm{~N}$

Beckham, K., 223N

Beet pseudo yellows virus

- on blackberry, first report USA, 223N

-on pumpkin, in California, $82 \mathrm{~N}$

Begonia, Fusarium wilt, first report in USA, $1287 \mathrm{~N}$

Bélair, G., 989

Belisario, A., 426N

Beltrán, R., $84 \mathrm{~N}$

Bergdahl, D. R., 359, 1085

Berger, P. H., 368

Berner, D. K., 316, 804, 1161N, 1382N

Bernier, L., 770N

Bertetti, D., 311N, 572N, 681N, 682N, 905N

Bextine, B. R., 600

Bezerra do Nascimento, I. J., 84N

Bhat, R. G., 49

Bi, Y., 896

Biasoli, M., 1044N

Biggs, A. R., 147

Biller, C. R., 1287N

Bioherbicide, Drechslera gigantea and Pyricularia setariae, for green foxtail, 605

Biological control

—alfalfa blossom blight, control conditions, 1246

- apple and pear to fire blight, disease forecasting, 41

-bacteriophage for tomato bacterial spot, SAR inducers, 736

-Cryptococcus laurentii for jujube fruit disease, postharvest, 497

-Drechslera and Pyricularia spp. for green foxtail control, 605

- Pseudomonas for bacterial wilt on tomato, 669

- Pseudomonas syringae for apple blue mold, postharvest decay, 662

- Rhodotorula glutinis for Botrytis cinerea, vinclozolin role, 1262

- seed bacteria for rice sheath blight, developing countries, symposium, 557

- Trichoderma hamatum for Phytophthora crown rot and leaf blight of cucumber, 280

-Trichoderma koningii for onion white rot, 287

Blackberry

-Beet pseudo yellows virus, first report in USA, $223 \mathrm{~N}$

-rosette, floral bud development, 195

Blaisdell, G. K., 574N 
Blanco, C., 878

Blanco, R., 1383N

Block, C. C, 633

Blodgett, J. T., 311N, 333

Blok, W. J., 688

Blueberry

- Septoria leaf spot, photosynthesis and leaf damage, 397

Blueberry scorch virus

-on blueberry, Connecticut and Massachusetts, $572 \mathrm{~N}$

-on cranberry, Canada and USA, 427N

Boal, R. J., 223N, 413

Bobev, S. G., $427 \mathrm{~N}$

Bockus, W. W., 530

Boehm, M. J., 175

Boland, G. J., 891

Bonde, M. R., 56, 316, 804

Booyse, M., 474

Borago officinalis, Pseudomonas cichorii on, Spain, $769 \mathrm{~N}$

Boso, S., 741

Botella, L., 1189

Botryosphaeria spp., sporulation, temperature effect, 292

- B. dothidea: on apple, inoculum and calcium, 147; on Arbutus menziesii, disease progression, 852

-B. obtusa, on grape, Chile, $1286 \mathrm{~N}$

Botrytis spp., on onion seed, prevalence in Washington, 1061

- B. aclada, on onion, seed infection, cover photo, October

-B. cinerea: on hydrangea, Buenos Aires, $1160 \mathrm{~N}$; on pansy, Buenos Aires, 1164N; on pear, tree and postharvest decay, 468; on substrates, disinfestants, 509

Bottner, K. D., 429N

Bourassa, M., $85 \mathrm{~N}$

Bové, J. M., 453, 1189

Bowers, J. H., 11

Boyetchko, S. M., 605

Brachiaria spp., endophytic fungus, seed transmission, 1252

Bradley, C. A., 1123, 1287N

Brannen, P. M., 1000

Brassica spp., Radish mosaic virus, Iran, 909N

-B. napus, Sclerotinia stem rot, resistance evaluation techniques, 1033

Brecht, M. O., 338

Bremia lactucae, on lettuce, fungicide resistance, 502

Brenneman, T. B., 858

Brenneria nigrifluens, on walnut, in France, $220 \mathrm{~N}$

Bridges, W. C., 1000

Britton, K. O., 951

Brlansky, R. H., 1049N

Broucqsault, L. M., 1213

Broussonetia papyrifera, witches'-broom, elm yellows phytoplasma association, $770 \mathrm{~N}$

Brown, L. G., 935

Brown, S., 502

Brown-Guedira, G. L., 530

Bruna, A., 1286N

Bryson, P. K., 1000

Buchwaldt, L., 4, 308

Buck, J. W., 657, 1262

Bull, C. T., 1384N

Buonaurio, R., $425 \mathrm{~N}$

Buresti, E., $1048 \mathrm{~N}$

Bushe, B. C., 1318

Butler, D. R., 797

Butternut, canker, conidial viability, in beetle skeletons, 1085

Cadena-Hinojosa, M., 29

Cadio, L., 1046N

Café-Filho, A. C., 573N
Cajza, M., $1381 \mathrm{~N}$

Calonectria ilicicola, on soybean:

—factors, 613

-root colonization, temperature effect, 620

Camargo, L. E. A., 157, $1161 \mathrm{~N}$

Cambra, M. A., 453, 769N

Camera, digital, fundamentals of imagery, 228

Cammue, B. P. A., $86 \mathrm{~N}$

Campbell, K. G., 1027

Canavalia ensiformis, Tobacco mosaic virus, Venezuela, $681 \mathrm{~N}$

"Candidatus liberibacter asiaticus," huanglongbing disease, Brazil, 1382N

Canola, powdery mildew, Argentina, 1163N

Cappelli, C., 425N

Capsicum аппиит

-anthracnose, management, fungicides, 1198

-bacterial spot: copper tolerance in Australian populations, 921; in Turkey, $85 \mathrm{~N}$

-Pepper mild mottle virus, detection in field soil, 650

-Phytophthora capsici, soil salinity response, 205

-root-knot, double-cropping for nematode management, 589

-Tomato chlorosis virus, natural host, $224 \mathrm{~N}$

Carannante, G., $425 \mathrm{~N}$

Carballo, O., 681N

Carrot

-Alternaria diseases, feature, 776

—bacterial leaf blight, PCR-based assay, 1226

Caruana, M. L., 119

Cashew, powdery mildew, South Africa, $1284 \mathrm{~N}$

Cassava, viruses, Kenya, 17

Castilla, N. P., 1310

Castlebury, L. A., 222N, 427N

Causin, R., 1048N

Centaurea solstitialis, leaf spot, Greece, 1382N

Cepeda, R., 1050N

Ceratocystis fimbriata, on Eucalyptus, resistance, 758

Cercospora arachidicola, on peanut, tillage, cultivars, and fungicide effects, 858

Cercosporella sp., on Centaurea solstitialis, leaf spot in Greece, $1382 \mathrm{~N}$

-C. rubi, on blackberry, floral bud development, 195

Cetinkaya-Yildiz, R., 310N, 907N

Cevik, B., 935

Chabrier, C., 1189

Chaloux, P. H., 1179

Chang, C. A., $1046 \mathrm{~N}$

Chang, C. J., 951

Charlet, D. A., 772N

Chastaganer, G. A., 188

Cheheid, A., 1383N

Chen, C. C., $1046 \mathrm{~N}$

Chen, W., $310 \mathrm{~N}$

Chen, X., 896

Cheng, Y.-H., 594

Cherry virus A, Little cherry virus-1 comparison, Poland, $909 \mathrm{~N}$

Chickpea chlorotic dwarf virus, on chickpea, Syria, 424N

Chioanthus retusis, anthracnose, Delaware, $427 \mathrm{~N}$

Chongo, G., 4, 308

Choo, T. M., 837

Chrestin, H., 1046N, 1047N

Cicer arietinum, Ascochyta blight, genetic diversity, Canada, 4, 308

Cieślińska, M., $909 \mathrm{~N}$

Cirsium arvense, powdery mildew, first report in North America, $312 \mathrm{~N}$

Citrus

—anthracnose, benomyl sensitivity, 125

- canker: new strain from lime and alemow, 1179; resistance and triploid hybrids, screening, 1056; systemic resistance, control, 745

— graft-transmissible pathogens, bioindexing, 1328

-melanose, pycnidium production, factors, 379

- postbloom fruit drop, fungicide spray timing, 731

—-sudden death, graft-transmissible, Brazil, 453

- viroid prevalence, Tunisia, $1286 \mathrm{~N}$

- viroids, growth and yield affected by graft, 1189

Citrus mosaic virus, on orange, capsid polyprotein gene in transgenic lines, 865

Citrus reticulata, witches'-broom, Iran, $683 \mathrm{~N}$

Citrus tristeza virus

-on citrus, vectors, cover photo, September

- detection using RT-PCR field trees, 625

-sudden death symptom, Brazil, 453

Citrus viroid 4, on orange, cover photo, November

Citrus viroid IIIb, Poncirus trifoliata, host interaction, irrigation, 709

Clarkson, J. P., 695

Clavibacter michiganense, on tomato:

-in Indonesia, $680 \mathrm{~N}$

-in Turkey, $1048 \mathrm{~N}$

Claviceps spp., host range and distribution in USA, 63

Clonostachys rosea, alfalfa blossom blight control, 1246

Clover yellow mosaic virus, on Verbena canadensis, in Florida, 223N

Cochliobolus sativus, rice-wheat system in Asia, control, symposium, 552

Coleoptera, skeletons inhabited by Sirococcus clavigignenti-juglandacearum, 1085

Coletta-Filho, H. D., 1382N

Colletotrichum spp.: on apple, population diversity in North Carolina, 1335; on Crupina vulgaris, Greece, $1161 \mathrm{~N}$; on Liriodendron tulipifera, Argentina, 1381N; on strawberry, detection, 407; on strawberry, screening method, 845

-C. acutatum: on azalea, leaf spot in Italy, $572 \mathrm{~N}$; on citrus, C. gloeosporioides comparison, benomyl sensitivity, 125 ; on citrus, fungicide spray timing, 731; on pepper, management, 1198; on tulip tree, with $C$. gloeosporioides, cover photo, December

-C. graminicola, genetic variation, isozyme analysis of hosts, 402

-C. lindemuthianum, on Phaseolus vulgaris, pathotypes in Mexico, 152

-C. malvarum, on Althaea officinalis, Italy, $425 \mathrm{~N}$

Computer, race-specific resistance genes, program, 545

Confer, B. M., 316

Connolly, T., 605

Cook, M. J., IV, 1285N

Cooke, L. R., $771 \mathrm{~N}$

Cooksey, D. A., 1255

Copes, W. E., 188, 292, 509

Coramusi, A., 426N

Corazza, L., $426 \mathrm{~N}$

Córdova, M. C., 906N, 908N

Coriandrum sativum, bacterial leaf blight, Taiwan, $910 \mathrm{~N}$

Corn (see also Maize)

- Rhizoctonia solani in AG-13, Mississippi, $908 \mathrm{~N}$

Correa-Victoria, F. J., 253

Correll, J. C., 84N

Corylus avellana, Alternaria spp. groups, $426 \mathrm{~N}$

Costa, H. S., 1255

Côté, M.-J., 1219

Cotton

—nematodes, old and new challenges, 100

—reniform nematode, Virginia, $683 \mathrm{~N}$ 
Cotty, P. J., 1366

Cottyn, B., 557

Cover photo

-Alternaria radicina, on carrot, black rot, August

-Amaranthus hybridus, stem infections, April

-Apple stem pitting virus, stony pit, May

-Ascochyta rabiei, on chickpea, blight, January

- citrus, Xanthomonas axonopodis, canker lesions, October; Xanthomonas exopodis, canker, November

- Citrus tristeza virus, on citrus, Florida, September

-Colletotrichum acutatum and $C$. gloeosporioides, on tulip tree, leaf blotch, December

-Cronartium ribicola, on bristlecone pine, March

— cucumber, root-knot nematode, root galling, June

-Erwinia amylovora, on cotoneaster, fire blight, July

-Fusarium oxysporum: on banana, wilt symptoms, June; on golden barrel cactus, stem rot, February

-Fusarium oxysporum f. sp. niveum, on watermelon, wilt, December

-Fusarium solani f. sp. glycines, on soybean, sudden death syndrome, December

-Hoplolaimus columbus, on cotton, stunting, February

- Hop stunt viroid and Citrus viroid 4, on orange, November

-Iris yellow spot virus, on onion, foliar symptoms, May

-lettuce, root knot, combined species, January

-Melampsora sp., on Salix bebbiana, rose gall, January

- Monilinia fructicola on nectarine, November

-onion, Botrytis aclada on seed, October

-Papaya ringspot virus, on fruit, June

-Phomopsis viticola, on grape, cane and leaf spot, September

- Pigeonpea sterility mosaic virus, leaf symptoms, May

-Plasmopara obducens, on impatiens, symptoms, August

-Pseudomonas syringae on cauliflower, leaf spot symptoms, July

- Ramularia sphaeroidea, on lana woollypod vetch, leaf spot, February

-Sclerotinia sclerotiorum: on petunia, white mold, April; on dry bean, white mold, December

- Sclerotium rolfsii, on laurustinus, March

-Septoria pistacearum, on pistachio, leaf spot, April

-Silphium laciniatum, stem blight, symptoms, October

-Sphaeropsis pyriputrescens, on pear, stemend rot, February

- Streptomyces acidiscabies, on radish, lesions, August

—Tobacco mild green mosaic virus, color-break symptoms, July

-Tomato spotted wilt virus, on peanut, March

-Toxoptera citricida, Citrus tristeza virus, Florida, September

-Uncinula tulasnei, on Norway maple, September

Cox, T. S., 530

Coyne, D. P., 830

Cramer, C., $1049 \mathrm{~N}$

Cranberry

-Blueberry scorch virus, Canada and USA, $427 \mathrm{~N}$

-fruit rot, postharvest, Michigan, 1277

Creamer, R., $1049 \mathrm{~N}$
Crepel, C., $427 \mathrm{~N}$

Crinipellis perniciosa, on cacao, resistance assessment, segregating populations, 797

Crinivirus sp., on strawberry, pallidosis association, 383

Cronartium ribicola

-on bristlecone pine: cover photo, March; first report, $311 \mathrm{~N}$

-on Pinus albicaulis and Ribes spp., Nevada, $772 \mathrm{~N}$

Cronshaw, K., 537

Crous, P. W., 221N

Crow, W. T., 680N

Crucifer, black spot, seedborne Alternaria, 490

Crupina vulgaris, anthracnose, in Greece, $1161 \mathrm{~N}$

Cryptococcus laurentii, biocontrol agent, jujube fruit disease, fungicides, 497

Csinos, A. C., $1285 \mathrm{~N}$

Csinos, A. S., 771N

Cuadrado, I. M., 1162N

Cubero, J., 1179

Cucumber

-black root rot, in Italy, $425 \mathrm{~N}$

-Fusarium wilt, isolate characterization, vegetative compatibility group, China, 645

- Phytophthora crown rot and leaf blight, biocontrol with Trichoderma hamatum, 280

—root-knot nematode: double-cropping, bell pepper, 589; root galls, cover photo, June

—Zucchini yellow mosaic virus, India, 906N

Cucumber leaf spot virus, in Poland, 1381N

Cucumber mosaic virus

—on Eryngium yuccifolium, Ohio, 1384N

-on Gerbera jamesonii, in India, 1161N

Cucumis melo

- Cucurbit aphid-borne yellows virus, Spain, $907 \mathrm{~N}$

-powdery mildew, race 2 in Brazil, $1161 \mathrm{~N}$

Cucurbit aphid-borne yellows virus, in Spain, 907N

Cucurbita pepo, Tomato yellow leaf curl virus, in Cuba, $572 \mathrm{~N}$

Culbreath, A. K., 259, 858

Curry, K. J., 195

Curvularia affinis, on Festuca arundinacea, leaf spot in China, $1048 \mathrm{~N}$

Cymbidium mosaic virus, on vanilla, French Polynesia, 119

Cynodon dactylon, spring dead spot, genetic diversity, 1341

Cyperus spp., C. esculentus and C. rotundus, Impatiens necrotic spot virus on, Georgia, $771 \mathrm{~N}$

Cytospora chrysosperma, on white poplar, in Israel, 220N

Dagert, M., 516

Dai, Y. C., $573 \mathrm{~N}$

Dalisay, T. U., 1310

Dangi, O. P., 989

Danielson, G. A., 297

Datnoff, L. E., 253, 338

Dauphinais, N., 989

Davidson, F., 119

Davis, J. R., 1168

Davis, M. J., 352

Davis, R. E., $770 \mathrm{~N}$

Davis, R. F., 589

Davis, R. M., 776, 1226

Davison, D. A., 935

Day, K. R., 222N

Deahl, K. L., 771N

De Boer, S. H., 363

De Cal, A., 210

de Cara, M., $1383 \mathrm{~N}$

DeHaan, T.-L., 363

Delatte, H., 681N

Della Vecchia, P. T., 1161N
Delort, F., 220N

de los Santos, B., 878

del Río, L. E., 1352

DeMarsay, A., 572N

Dendy, S. P., 574N

De Negri, J. D., 1382N

Dennis, J. J. C., 287

Derie, M. L., 1061

de Souza Freitas, L., 84N

de Vicente, A., $905 \mathrm{~N}$

Diaporthe spp.

-D. citri, on citrus, pycnidium production, factors, 379

-D. perjuncta, on grape, nonpathogenic, Australia, 1005

-D. phaseolorum, on soybean, Wisconsin, $576 \mathrm{~N}$

Díaz-Valasis, M., 29

Dickstein, E. R., 85N, 1048N, 1050N

Dieffenbachia amoena, bacterial stem rot, outbreak in Turkey, $310 \mathrm{~N}$

Diehl, S. V., 195

Diers, B. W., 761

Digital imagery, fundamentals and applications, 228

Dill-Macky, R., 724

Dimenna, S., $1381 \mathrm{~N}$

Diplotaxis tenuifolia, downy mildew, Italy, $1381 \mathrm{~N}$

Discula fraxinea

-on ash, Oregon, $222 \mathrm{~N}$

-on fringetree and white ash, in Delaware, $427 \mathrm{~N}$

Disease control

-developing countries, symposium, 550

- sustainable, ten thousand years of experience, symposium, 550

Disease forecasting, fire blight on apple and pear, biocontrol, 41

Disease management, propiconazole for stone fruits, Georgia, 1000

Dixon, W. N., 1179

Djavaheri, M., 683N

Domier, L. L., $1285 \mathrm{~N}$

Dongyi, H., 1252

Drechslera gigantea, on green foxtail, moisture and temperature effect, 605

Drouillard, D. L., 1056

Druffel, K. L., 222N

Du, P. V., 557

Dubois, A., 1189

Dubois, C., 1189

Dugan, F. M., 83N, 310N

Dumenyo, C. K., 1255

Duran-Vila, N., 453,1046N, 1189, 1286N

du Toit, L. J., 222N, 1061

Duveiller, E., 552

Eastburn, D. M., 1011

Echinocactus grusonii, basal stem rot, first report in Italy, $85 \mathrm{~N}$

Eckhardt, L. G., 1174

Eisenback, J. D., 683N

Eizenberg, H., 1284N

Elazegui, F. A., 1310

Eleagnus angustifolia, twig canker, Italy, 1048N

Elmer, W. H., 1287N

Elmhirst, J. F., 575N

Embleton, J., 680N

Emblica officinalis, black soft rot, $575 \mathrm{~N}$

Endres, G. J., 1123

Englander, L., 993

Engle, J. S., 175

Ens, W., 824

Enterobacter cloacae, on ginger, Hawaii, 1318

Erickson, R. S., 1246

Erratum, vol. 88, no. 1, 2004, 308

Eruca spp.

-E. sativa, clubroot, Brazil, 573N 
-E. vesicaria, bacterial blight, California, $1384 \mathrm{~N}$

Erwinia spp.

-E. amylovora: on apple, prohexadionecalcium dose level, 1099; on cotoneaster, fire blight symptoms, cover photo, July; on Pyracantha coccinea, fire blight, Bulgaria, $427 \mathrm{~N}$

-E. carotovora, on Dieffenbachia amoena, outbreak in Turkey, $310 \mathrm{~N}$

-E. stewartii, on maize seed, seed health test, 633

Eryngium yuccifolium, Cucumber mosaic virus, Ohio, 1384N

Erysiphe spp.

-E. aquilegiae, on Aquilegia flabellata, in Italy, $681 \mathrm{~N}$

-E. cichoracearum, on thistle, first report in North America, 312N

-E. heraclei: on chervil, California, first report, $1163 \mathrm{~N}$; on dill, Spain, $905 \mathrm{~N}$

-E. polygoni: on canola, Argentina, $1163 \mathrm{~N}$; on sugar beet, perfect stage in Nebraska, 1049N

-E. viburni, on Viburnum tinus, California, $425 \mathrm{~N}$

Eskalen, A., $1285 \mathrm{~N}$

Eskandari, F. M., 1161N, 1382N

Eskridge, K. M., 830

Esperón, J., 1383N

Esterio, M., $1285 \mathrm{~N}, 1286 \mathrm{~N}$

Estrada, F. J., 1383N

Etienne, M., 837

Eucalyptus spp., Ceratocystis fimbriata, resistance clones, 758

Eustoma grandiflorum

-Fusarium solani, South Africa, 573N

- Phytophthora palmivora, root rot and stem blight, $224 \mathrm{~N}$

Eutypa lata, PCR-RFLP for identification, 925

Everts, K. L., 1357

Fakhfakh, H., 1164N

Falk, D. E., 837

Fan, L., 557

Fan, Z. F., 683N

Fareyrol, K., 119

Farrar, J. J., 309N, 776

Farzadfar, Sh., 424N, 909N, 1069

Feau, N., 770N

Fedak, G., 837

Fegan, R. M., 1040

Fekih Hassen, I., 1164N

Felicia amelloides, white mold, in Italy, 575N

Fermin, G., 516

Fernández, E. J., 1383N

Fernández-Pavía, S. P., 29, 1283N

Fery, R. L., 589

Festuca arundinacea, leaf spot, China, 1048N

Ficus benjamina, Agrobacterium sp. from, Spain, 428N

Fidanza, M., 1146

Figueroa-Lopez, P., 703

Figuli, P., 426N

Fisher Gregory, N., 427N

Flax, pasmo, fungicides and cultivars, management, 1123

Flores, A., 1046N

Focus, 2, 99, 227,315, 435, 579, 687, 775, 915, $1055,1167,1291$

Fogle, D., 1163N

Fonseca, D., 572N

Font, M. I., 82N

Fortunella margarita, Lasiodiplodia

theobromae, Taiwan, 1383N

Fourie, P. H., 1241

Fournier, Y., 989

Fragkiadakis, G. A., 645

Fraxinus americana, anthracnose, in Delaware, $427 \mathrm{~N}$
Freeman, S., 845

Frey, P., 85N

Fry, J. D., 134

Fry, W. E., 29

Fujita, S., 875

Fujita, Y., 265

Fumigant, methyl bromide, strawberry nurseries, 210

Funderburk, J. E., 882

Fungicides (general) (see also Fungicides, specific)

—alfalfa, Verticillium wilt, 811

—anthracnose on pepper, management, 1198

— citrus canker, systemic resistance compounds, 745

— citrus fruit drop, spray timing, 731

-flax pasmo, management in North Dakota, 1123

-floriculture crops, rust control, timing effect, 657

- grape powdery mildew, sensitivity, 1205

- jujube fruit disease, postharvest, 497

-lettuce, Sclerotinia drop, 665

- peanut early leaf spot, tillage and cultivar effects, 858

- Phomopsis seed decay in soybean, 721

—potato early blight, $\mathrm{Q}_{\mathrm{o}} \mathrm{I}$ fungicides, 181

-rice blast, with silicon, 253

- stone fruit, Monilinia fructicola sensitivity, 373

— turfgrass, application runoff, 391

-wheat stripe rust, epidemic in China, 896

Fungicides (specific) (see also Fungicides, general)

-benomyl, Colletotrichum spp. sensitivity, on citrus, 125

- chlorothalonil, gray leaf spot on St. Augustinegrass, silicon, 338

- dimethomorph, potato late blight resistance, 930

- ethofumesate, ryegrass, gray leaf spot, timing, 1146

-fosetyl-aluminum, Bremia lactucae resistance, 502

- mefenoxam: Phytophthora cactorum resistance, $576 \mathrm{~N}$; potato pink rot and leak tuber control, 301

- phosphorous acid, potato tuber rots, foliar applications, 1153

— propamocarb and mefenoxam, Pythium resistance, greenhouses, 630

- propiconazole, Monilinia fructicola in stone fruits, Georgia, 1000

-QoI, Venturia inaequalis resistance, 537

- thiabendazole, pear postharvest decay control, 474

- vinclozolin, role in yeast for Botrytis cinerea, 1262

Furtado, E. L., 731

Fusarium spp.

-F. circinatum, on Douglas-fir, California, $772 \mathrm{~N}$

$-F$. foetens, on begonia, first report in USA, $1287 \mathrm{~N}$

-F. graminearum: on barley, cultivar response and deoxynivalenol accumulation, 837; on barley, resistance, 167; growth, choline, betaine, and floral extracts, 175; on soybean, pathogen, $220 \mathrm{~N}$

-F. oxysporum: on banana, wilt symptoms, cover photo, June; on cactus, basal stem rot, cover photo, February; on cactus, stem rot in Italy, $85 \mathrm{~N}$; chlorine dioxide effect, 188; on cucumber, vegetative compatibility group, China, 645; on Gerbera, in Italy, 311N; on melon, race 1 in Mexico, $1383 \mathrm{~N}$; on Osteospermum sp., in Italy, 309N; on Valerianella olitoria, in Italy, $83 \mathrm{~N}$; on watermelon, suppression by hairy vetch amendment, 1357

-F. oxysporum f. sp. niveum: on watermelon, wilt, cover photo, December

-F. solani: on lisianthus, South Africa, $573 \mathrm{~N}$ on soybean, PCR for detection, 1372; on soybean, sudden death syndrome, root systems, 1011; on St. John's wort, crown and root rot in Argentina, 1050N

-F. solani f. sp. glycines: on soybean, sudden death syndrome, cover photo, December

$-F$. tucumaniae and $F$. virguliforme, on soybean, sudden death in Argentina, 1044N

Fusicladosporium carpophilum, on peach, fungicide and costs, 162

Gadoury, D. M., 869

Gaetán, S., 1050N, 1163N

Gao, X., 1372

Garay-Serrano, E., 1283N

Garbelotto, M., 430N

Garboza, C., 516

García-Jiménez, J., 84N

Garg, N., $575 \mathrm{~N}$

Garibaldi, A., 82N, 83N, 309N, 311N, 312N, $572 \mathrm{~N}, 575 \mathrm{~N}, 681 \mathrm{~N}, 682 \mathrm{~N}, 905 \mathrm{~N}, 1044 \mathrm{~N}$, $1045 \mathrm{~N}, 1381 \mathrm{~N}$

Garnsey, S. M., 1328

Garrett, K. A., 565, 574N

Gasoni, L., 86N

Geiser, D. M., 1287N

Genc, H., 935

Geranium, Botrytis cinerea, Rhodotorula glutinis as biocontrol, 1262

Geranium carolinianum, stem and leaf blight, North Carolina, 312N

Gerbera jamesonii

- Cucumber mosaic virus, India, $1161 \mathrm{~N}$

-Fusarium wilt, in Italy, 311N

Germán, S. E., 1162N

Ghasemi, A., 1069

Ghulam, W., 424N

Gibberella zeae, on wheat, survival in residue, 724

Gilardi, G., 82N, 83N

Gilbert, J., 167

Gilbertson, R. L., 1226

Gilles, T., 695

Gil-Salas, F. M., 1162N

Gimenes-Fernandes, N., 453

Giorda, L., 1044N

Girotto, L. F., 453

Gispert, C., 1255

Gitaitis, R. D., $1285 \mathrm{~N}$

Goldman, P., 1384N

Goldring, L. V., 1384N

Golnaraghi, A. R., 424N, 909N, 1069

Golovinomyces cichoracearum, on potato, California, 309N

Gomez, G., $1162 \mathrm{~N}$

Gómez, V., 905N

Gonatophragmium, on rice, causal agent of red stripe, 1310

Gonsalves, D., 516

González, A. J., 1382N

González, E., 1335

González-Chavira, M., 152

Gorbet, D. W., 259, 858

Gordon, D. T., 824

Gordon, T. R., 772N

Gossen, B. D., 4, 308

Gottwald, T. R., 1179

Goud, J.-K. C., 688

Graham, J. H., 745, 1056, 1179

Graham, T. L., 175

Grape

-Arabis mosaic virus and Grapevine leaf roll associated virus-3, Iran, $424 \mathrm{~N}$

-Armillaria root rot, postinfection control, 1235 
-black dead arm and basal canker, Chile, $1286 \mathrm{~N}$

- downy mildew, resistance in eight clones, 741

-Eutypa lata identification with PCR-RFLP, 925

—melting decay, in California, 1047N

-Petri disease, propagation material for control, 1241

-Phaeomoniella chlamydospora, French American hybrids in Chile, $1285 \mathrm{~N}$

-Phomopsis cane and leaf spot, Diaporthe perjuncta relation, 1005

- powdery mildew: perennation in vineyards, Washington, 242; trifloxystrobin, spiroxamine, and triadimefon, 1205

-Xylella fastidiosa: other hosts in California, 1255; xylem fluid collection techniques, 600

Grapevine leaf roll associated virus-3, on grape, Iran, 424N

Grau, C. R., 576N, 761, 769N, 1033

Gray, F. A., 811

Green, S. (Canada), 605

Green, S. K. (Taiwan), 311N

Greer, G. D., 1328

Gregoire, T., 1123

Griesbach, J. A., 87N

Grisoni, M., 119

Groenewald, J. Z., 221N

Grosser, J. W., 1056

Grove, G. G., 242

Growth regulator, prohexadione-calcium, apple fire blight effect, 1099

Grunden, E., 1139

Grünwald, N. J., 29, 310N, 1283N

Guan, X., 625

Guaragna, M. A., 574N

Gubler, W. D., 925, 1205, 1285N

Gudmestad, M. C., 429N

Gudmestad, N. C., 181, 301

Guerri, J., 906N

Guillemette, T., 490

Gullino, M. L., 82N, 83N, 309N, 311N, 312N, $572 \mathrm{~N}, 575 \mathrm{~N}, 681 \mathrm{~N}, 682 \mathrm{~N}, 905 \mathrm{~N}, 1044 \mathrm{~N}$, $1045 \mathrm{~N}, 1381 \mathrm{~N}$

Gumpf, D. J., 709, 1328

Haber, S., 824

Hagiwara, K., 650

Halbert, S. E., 935

Halgren, A. B., 383

Halik, S., 359, 1085

Hallan, V., 86N, 1161N

Halleen, F., 1241

Halley, S., 1123

Halse, R. R, 63

Hamelin, R. C., 85N

Hamilton, V. A., 921

Hanson, P., 311N

Hanssen, I. R. M., 86N

Harikrishnan, R., 817

Harrington, T. C., 758

Hartman, G. L., 325, 576N, 1372

Hartung, J. S., 1049N

Harveson, R. M., 1049N

Harvey, T. L., 824

Hausbeck, M. K., 1292

Hayashi, N., 265

He, Z., 896

Heath, J. J., 565

Hebe buxifolia, downy mildew, in Italy, 424N

Heijne, B., 751

Helianthus spp.

- H. annuus, downy mildew, races 700 and 703 in Italy, $1284 \mathrm{~N}$

-H. tuberosus, southern blight, California, $769 \mathrm{~N}$

Hellier, B. C., 83N

Helms, T. C., 297

Hendrix, F. F., Jr., 292
Henneberger, T. S. M., 951

Henriquez, J. L., 1134

Hepperly, P. R., 1318

Hernández-Godínez, F., 152

Hernandez-Martinez, R., 1255

Herrero, M. L., 1382N

Hershenhorn, J., 1284N

Heterodera glycines, on soybean

- cultivar resistance, North Carolina, 942

-North Dakota, 1287N

-resistance, relation to brown stem rot, 761

Hevea brasiliensis

—bark necrosis syndrome I, causal agent, $1046 \mathrm{~N}$

—bark necrosis syndrome II, causal stresses, $1047 \mathrm{~N}$

-bark necrosis syndrome III, physiological disease, cyanide metabolism, 1047N

Hibiscus, tobamovirus from, detection method, 34

Hibiscus latent Fort Pierce virus, on hibiscus, transmission and management, 674

Hibiscus rosa-sinensis, Tomato mosaic virus, China, 683N

Hiebert, E., 223N

Higashi, T., 650

Higginbotham, R. W., 1021, 1027

High Plains virus, variability, biological and molecular, 824

Hillman, B. I., 572N

Hirabayashi, T., 865

Hirayae, K., 265

Hixson, A. C., 680N

Ho, K. M., 837

Hoitink, H. A. J., 280

Hokanson, S. C., 383

Holb, I. J., 751

Holcomb, G. E., 770N

Holguín-Peña, R. J., 221N

Hollowell, J. E., 312N, 426N

Honda, Y., 650

Hong, C. X., $1283 \mathrm{~N}$

Hop stunt viroid

- Canada, first record, $1162 \mathrm{~N}$

-fruit trees, Tunisia, 1164N

-on orange, cover photo, November

Hopkins, N., 683N

Hoplolaimus columbus, on cotton, stunting, cover photo, February; feature, 100

Horowitz, S., 845

Horvath, B. J., 402

Hsiang, T., 1048N

Hsiao, C.-H., 594

Hsu, H. T., 1046N

Hu, J. S., $683 \mathrm{~N}$

Huang, H. (S.C.), 714

Huang, H. C. (Canada), 1246

Huang, J. B., 1048N

Huang, J. G., 683N

Huang, Q., 224N, 1049N

Huang, Z., 625

Hüberli, D., 430N

Hudelson, B. D., 769N

Huerta-Espino, J., 703

Hughes, M. E., 1079

Hughes, T. J., 761, 769N

Hugo, H. J., 574N

Huisman, O. C., 1168

Hummel, R. L., 188

Humulus lupulus

- phytoplasma, $908 \mathrm{~N}$

-Verticillium wilt, detection markers, 1115

Hurtt, S., 1347

Hutchinsia alpina, white mold, Italy, 1045N

Hwang, S.-C., 580

Hydrangea macrophylla, flower spot, Buenos Aires, $1160 \mathrm{~N}$

Hypericum perforatum, Fusarium crown and root rot, Argentina, 1050N
Hypolixus haerens, weevil on Amaranthus hybridus, fungi association, 333

Hyrondelle, C., 119

Iacomi-Vasilescu, B., 490

Ichiki, U. T., 650

Ikegashira, Y., 650

Ilex glabra, Phytophthora cinnamomi, Virginia, $1283 \mathrm{~N}$

Ilyas, S., $680 \mathrm{~N}$

Impatiens necrotic spot virus, on yellow and purple nutsedge, Georgia, 771N

Impatiens walleriana, downy mildew, California, $909 \mathrm{~N}$

Inglessis, V., 516

Inglis, D. A., 965, 1153

Innes, L., 85N

Instructions for authors, 90

Ipomoea purpurea, Phytophthora ipomoeae, in Mexico, $1283 \mathrm{~N}$

Iriarte, F. B., 1341

Iris yellow spot virus

-on Allium cepa, Georgia, $1285 \mathrm{~N}$

-on onion: bulbs and seeds, $222 \mathrm{~N}$; cover photo, May; in New Mexico, 1049N; thrips transmission, 446

Irish, B. M., $84 \mathrm{~N}$

Ito, T., 865

Iwanami, T., 865

Jackson, T. A., 345, 1372

Jaime-Garcia, R., 1366

Jain, R. K., 221N

Jakše, J., 1115

Jalali, S., 909N

James, D., 973

Janiolkowska, A., 1045N

Janisiewicz, W. J., 662

Jansky, S., 1075

Janssen, D., 1162N

Jaufeerally-Fakim, Y., 980

Javornik, B., 1115

Jeffers, S. N., 576N, 657, 714, 1262

Jeger, M. J., 751

Jesus Junior, W. C., 453

Jia, Q., 896

Jijakli, M. H., 1164N

Jin, S., 896

Joel, D. M., 1284N

Johnson, D. A., 419, 965, 1153

Johnson, K. B., 41

Johnston, R. H., 56

Jones, J. B., 85N, 669, 736, 1048N, 1050N, 1179

Jones, J. P., 1174

Jordá, C., 82N, 906N, 908N

Jordan, R. L., $574 \mathrm{~N}$

Juárez, J., 453

Juárez, M., 82N, 907N

Juglans regia (see also Walnut)

-Alternaria spp. groups, $426 \mathrm{~N}$

Kabir, Z., 49

Kaku, H., 1304

Kamenova, I., 34, 674

Kamińska, M., 908N, 1283N

Kane, S. F., 852

Karssen, G., 309N, 680N

Kashefi, J., 1161N, 1382N

Kauth, P. J., 1075

Keith, L. M., 1318

Kelemu, S., 1252

Keller, K. E., 383

Kennedy, R., 695

Khan, J., 280

Khoodoo, M. H. R., 980

Kidwell, K. K., 1021, 1027

Kim, O.-S., 641

Kim, P. V., 557 
Kim, S. H., 630

Kim, Y. (Kans.), 530

Kim, Y.-H. (Korea), 641

Kimchi, M., 220N

King, A. I., 1163N

King, R. R., 680N

Kirk, W. W., 930

Kirkpatrick, S. C., 772N

Kirkpatrick, T. L., 100, 345

Kitajima, E. W., 453

Klemsdal, S., 224N

Klepzig, K. D., 1174

Kloepper, J. W., 669

Kloudova, K., 906N

Knodel, J. J., 1123

Knoetze, R., 574N

Ko, W. H., 580, 1383N

Kobayashi, K., 86N

Kobori, R. F., $1161 \mathrm{~N}$

Koch, D. W., 811

Koenning, S. R., 100, 942

Kohn, L. M., 891

Koike, S. T., 221N, 425N, 502, 769N, 909N, $1163 \mathrm{~N}, 1384 \mathrm{~N}$

Köller, W., 537

Kolmer, J. A., 1079, 1127

Komorowska, B., 909N

Kondo, N., 875

Kopittke, R. A., 921

Korsten, L., 959

Kovalenko, E. M., 973

Kravchenko, A. N., 1277

Krueger, W. H., 131

Kucharek, T. A., 253, 338

Kulkarni, N. K., 436

Kull, L. S., 325

Kullaya, A., 916

Kulshreshtha, S., 1161N

Kulshrestha, S., 86N

Kumari, S. G., 424N

Kummert, J., 1164N

Kuroda, K., 84N

Kurtzweil, N. C., 576N, 761

Kuruppu, P. U., 613, 620

Kusaba, M., 265

Kusek, M., 310N

Kyde, K. L., 993

Lacy, G. H., 1179

Laemmlen, F., 502

Lagenaria siceraria, Zucchini yellow mosaic virus, India, $426 \mathrm{~N}$

Lambert, K. N., 1372

Lamey, H. A., 1352

Lamour, K. H., 1292

Landa, T., $1284 \mathrm{~N}$

Langston, D. B., Jr., 589, 1285N

Lapidot, M., 1160N

Larsen, R. C., 769N

Lasiodiplodia theobromae, on kumquat, Taiwan, $1383 \mathrm{~N}$

Lava Kumar, P., 436

Lavandula officinalis, Alfalfa mosaic virus, Spain, $908 \mathrm{~N}$

Lawrence, H. C., 680N

Layne, D. R., 162, 714

Lee, I.-M., 429N

Lee, J.-Y., 641

Lee, R. F., 935

Lee, S.-C., 641

Lee, Y.-A., $910 \mathrm{~N}$

Legard, D. E., 407

Leite, R. P., Jr., 157, 745

Lennox, C. L., 474

Lentil, Pythium irregulare, first report in USA, $310 \mathrm{~N}$

Leonard, K. J., 271

Leptographicum spp., loblolly pine decline association, pathogenicity, 1174
Le Saux, M., 220N

Lesemann, D.-E., 424N

Lett, J. M., 681N

Letters, potato early dying, management, 1168; response to Davis and Huisman, 1172

Lettuce

- downy mildew, fungicide resistance, California, 502

—drop, fungicides, 665

—wilt and leaf blight, Spain, 1382N

Lettuce big vein virus, first report in Chile, $1286 \mathrm{~N}$

Lewis Ivey, M. L., 1198

Leyronas, C., 1213

Li, D.-B., 645

Li, G. (Northwestern Univ., China), 896

Li, G. Q. (Huazhong Ag. Univ., China), 1246

Li, H. F., 683N

Li, R., 1347

Li, S., 576N, 1372

Li, W., $1049 \mathrm{~N}$

Lievens, B., 86N

Lin, C.-Y., 594

Linderman, R. G., 87N

Liou, P.-C., 594

Lipps, P. E., 175

Liriodendron tulipifera, Colletotrichum spp., Argentina, $1381 \mathrm{~N}$

Little cherry virus, sequence variability, British Columbia, 1092

Liu, H.-L., 909N

Liu, H. Y., $311 \mathrm{~N}$

Liu, Q., 770N

Liu, Y.-H., 909N

Llorente, I., 215

Locke, J. C., 11

Lolium perenne (see also Turfgrass)

- gray leaf spot, ethofumesate application, timing, 1146

— stem rust, planting date and age effect, 1017

Long, D. L., 271, 1079

López, M. M., 428N, 769N

Lopez, S. E., 1160N, 1164N

Lopez-Aranda, J. M., 210

López-Montoya, O., 905N

Lori, G. A., $1381 \mathrm{~N}$

Louie, R., 824

Louw, S. vdM., 333

Lozano, G., 224N, 428N

Lozoya-Saldaña, H., 1283N

Lucerne (see also Alfalfa)

-foliar diseases in France, new, 1213

Luffman, M., 1162N

Lukach, J. R., 1123

Lunak, G. A., $772 \mathrm{~N}$

Lunicera caprifolium, powdery mildew, Italy, $1045 \mathrm{~N}$

Luo, C. X., 265

Luo, Y., 373

Lupien, S. L., 83N

Luque, A., 1044N

Lyman, M. R., 195

Lynch, S. C., 852

Ma, Z., 373

Maas, J. L., 383

Maccaroni, M., 426N

Machado, M. A., 1382N

MacHardy, W. E., 869

Madar, Z., 220N

Madden, L. V., 280

Madia, M., 1050N, 1163N

Maes, M., 427N

Magnaporthe spp.

-M. grisea: on rice, silicon and fungicide effect, 253; on St. Augustinegrass, silicon and chlorothalonil effect, 338

$-M$. oryzae, avirulence and resistance genes, 265
Maiss, E., 17

Maize (see also Corn)

- chemical seed treatment, Erwinia infection, health test, 633

-High Plains virus, variability, 824

Makkouk, K. M., 424N

Malan, A. P., 574N

Maloney, P. E., 852

Malvick, D. K., 1139

Mandal, B., 259, 428N

Mandal, S., $428 \mathrm{~N}$

Mandevilla splendens, powdery mildew, Italy, $682 \mathrm{~N}$

Manjunath, K. L., 935

Marbot, S., 1164N

Marchand, L., $85 \mathrm{~N}$

Marois, J. J., 669, 882

Marrakchi, M., 1164N

Martin, D. L., 1341

Martin, G., $1162 \mathrm{~N}$

Martin, H. L., 921

Martin, R. A., 837

Martin, R. R., 223N, 383, 427N, 575N, 907N

Martin, T. J., 824

Martínez, M. C., 741

Martínez, O., 82N

Martínez de la Vega, O., 152

Martínez-Ochoa, N., 771N

Martínez-Priego, L1., 906N, 908N

Martinez-Treceño, A., 210

Martinez-Zubiaur, Y., 572N

Marys, E., 681N

Matheron, M. E., 665

Mathiasen, R., $1046 \mathrm{~N}$

Mathre, D. E., 56

McCallum, B. D., 167

McCarron, J. K., 574N

McCarthy, P. L., 383

McGee, D. C., 633

McGovern, R. J., 1040

McIntosh, C. S., 248

McMullen, M., 1123

McNitt, A. S., 1146

McVey, D. V., 271

Melampsora larici-populina, on Populus spp., in Eastern North America, 85N

Meldrum, A. J., 1219

Melgarejo, P., 210

Meloidogyne spp.

- M. ethiopica, on tomato, in Slovenia, $680 \mathrm{~N}$

$-M$. hapla, on lettuce, $M$. incognita comparison, cover photo, January

$-M$. incognita, on cucumber and squash, double-cropping, management, 589

- M. japonica, on buchu, South Africa, 574N

- M. marylandi on turfgrass, Israel, 309N

Melon

-Fusarium wilt, race 1 in Mexico, 1383N

-Monosporascus cannonballus, in Brazil, 84N

Ménard, M., 220N

Meng, J., 1033

Meng, X. Q., 1226

Mentha sp., Strawberry latent ringspot virus, first in North America, 907N

Mertelik, J., 906N

Mertely, J. C., 407

Metcalf, D. A., 287

Mew, T. W., 557, 1310

Michailides, T. J., 222N, 373, 1047N

Michelmore, R. W., 502

Michelutti, R., 1162N

Michener, P. M., 633

Microbacterium sp., on rice, histopathology, 1304

Miklas, P. N., 429N

Miller, G., 589

Miller, J. S., 1153

Miller, L., 368

Miller, S. A., 280, 1198 
Miller, S. S., 1099

Miller, T. A., 600

Miller, T. C., 1205

Milus, E. A., 136, 545, 1107

Minsavage, G. V., $85 \mathrm{~N}$

Minuto, A., 309N, 311N, 312N, 575N, 682N, $1044 \mathrm{~N}, 1045 \mathrm{~N}, 1381 \mathrm{~N}$

Minuto, G., 312N, 1381N

Mirafiori lettuce virus, first report in Chile, $1286 \mathrm{~N}$

Miranda, H., $1046 \mathrm{~N}$

Mirik, M., 310N, 907N

Mischke, S., 1269

Mizubuti, E. S., 758

Model, MILIONCAST, onion downy mildew, 695

Mokra, V., 906N

Molina-Bravo, R., 1049N

Momol, M. T., 669, 736, 882

Mondal, S. N., 379

Monfort, W. S., 858

Monilia polystroma, on stone fruit, multiplex PCR for identification, 1219

Monilinia spp., on stone fruit, multiplex PCR for identification, 1219

-M. fructicola: on nectarine, brown rot, cover photo, November; propiconazole, sensitivity and disease management, Georgia, 1000; on stone fruit, fungicide sensitivity, 373

Monosporascus cannonballus, on melon, in Brazil, 84N

Montecchio, L., 1048N

Montesinos, E., 215

Montoya, S., $1383 \mathrm{~N}$

Moon, J.-K., 641

Moorman, G. W., 630, 1283N

Mor, M., 309N

Morandi, E. N., 220N

Moreau, R., 1047N

Morelock, T. E., 84N

Moreno, P., 453, $906 \mathrm{~N}$

Morgan, D. P., 222N, 1047N

Moriones, E., 224N

Morisigue, D. E., 1160N

Moscatelli, M., 23

Moya, A., 1049N

Mozzoni, L., 220N

Mueller, D. S., 657

Mueller, J. D., 100, 589

Mullis, S. W., $771 \mathrm{~N}, 1285 \mathrm{~N}$

Mulrooney, R. P., 427N

Muniyappa, V., 436

Munyaneza, J. E., 429N

Mycosphaerella fijiensis, on banana, Grand Bahama Island, 772N

Mycotoxin

-aflatoxin, in corn-cotton rotation, management, Texas, 1366

—deoxynivalenol, on barley, cultivar response, 837

Myrta, A., 1162N

Nagata, R. T., 338

Naito, S., 875

Najar, A., $1286 \mathrm{~N}$

Nakajima, T., 265

Nameth, S. G. P., 1384N

Nandris, D., 1046N, 1047N

Nasiruddin, K. M., 221N

Nava-Diaz, C., 1198

Navarro, L., 906N

Navas-Castillo, J., 224N, 428N

Navratil, M., 906N

Naze, F., 681N

Nazim, M., 271

Nectarine, sour rot, yeast cause, $222 \mathrm{~N}$

Nelson, B. D., 297, 1287N

Nelson, R. J., 565

Nematodes
- cotton, old and new challenges, 100

-on Paspalum vaginatum, in Florida, $680 \mathrm{~N}$

Neofabraea spp., on pear, etiology in Oregon,

Washington, and California, 1134

Nester, S. E., 316, 804

Newcombe, G., $312 \mathrm{~N}$

Niblack, T. L., 1372

Niblett, C. L., 935

Nicotiana spp. (see also Tobacco)

-N. megalosiphon, Potato virus A, new host, $1160 \mathrm{~N}$

Nilpanit, N., 557

Nischwitz, C., 312N

Nishijima, K. A., 1318

Nogueira, N. L., 573N

Nolte, P., 248

Norelli, J. L., 1099

Notsu, A., 875

Nuñez, J. J., 309N

Obradovic, A., 736

Ochoa, O. E., 502

Ocimum basilicum, downy mildew, in Italy, $312 \mathrm{~N}$

O’Donnell, K., 1044N

Oelke, L. M., 1127

Ohki, T., 650

Oidium spp.: on Akebia quinata, Italy, 682N; on Papaver nudicaule, Italy, 682N; on Spiraea, Italy, 1045N; subgenus Pseudoidium, on Mandevilla splendens, Italy, $682 \mathrm{~N}$

-O. anacardii, on cashew, South Africa, 1284N

-O. subgenus Pseudoidium: on honeysuckle, Italy, 1045N; on Salvia scabra, Italy, 682N

Oka, Y., 309N

Olatinwo, R. O., 1277

Oleander

—bacterial leaf scorch, Texas, 1049N

-Xylella fastidiosa, xylem fluid collection techniques, 600

Olexa, M. T., 1040

Olive, knot, copper sprays, factors, 131

Olsen, M. W., 316, 804

Olson, S. M., 669, 736, 882

Omura, T., 650

O’Neill, N. R., 1269

Onion

-Botrytis spp., seed infection, Washington, 106

—downy mildew, disease predicting model, 695

-Iris yellow spot virus: bulbs and seeds,

Washington, 222N; in Colorado, thrips, 446; New Mexico, 1049N

—rust, first report, $83 \mathrm{~N}$

-white rot, suppression by Trichoderma koningii, 287

Ooka, J. J., 280

Oomycetes, on potato, tuber rots, phosphorous acid application, 1153

Ophiosphaerella korrae, on bermudagrass, genetic diversity, 1341

Orange

-Citrus mosaic virus, capsid polyprotein gene, 865

— citrus viroids, growth and yield affected by graft, 1189

Orban, S., 1092

Ornamentals

- ericaceous, Phytophthora ramorum on, susceptibility, 993

-floriculture crops, fungicide applications, rust, 657

- Phytophthora ramorum, blight in Oregon nurseries, $87 \mathrm{~N}$

Orobanche spp., on sunflower, cultivar variation, 479

-O. umana, new race, Israel, $1284 \mathrm{~N}$

Orrego, R., 565

Ortega, E., $681 \mathrm{~N}$
Ortiz, O., 565

Ortiz-Ribbing, L. M., 1011

Osborn, T. C., 1033

Osteospermum sp., Fusarium wilt, Italy, 309N

Osterbauer, N. K., 87N

Oudemans, P. V., 572N

Ozias-Akins, P., 259

Pachira aquatica, Pythium splendens, stem rot, $84 \mathrm{~N}$

Palacio-Bielsa, A., 769N

Palenzuela, I., 572N

Pallás, V., 1162N

Palmquist, D., 325

Pamplona, R., 557

Pandey, B. K., 575N

Pandey, G., 575N

Pant, R. P., 221N, 426N

Papaver nudicaule, powdery mildew, Italy, $682 \mathrm{~N}$

Papaya ringspot virus

- coat protein gene, field test in Taiwan, 594

-fruit symptoms, cover photo, June

-on papaya, Bangladesh, 221N

- papaya resistance, transgenic, 352

-resistance engineered, Venezuela, 516

Pappu, H. R., 222N, 259

Parisella, R., $425 \mathrm{~N}$

Parke, J. L., 87N

Parker, D. M., 537

Parlavecchio, G., 310N, 424N

Pasche, J. S., 181

Paspalum vaginatum, nematode, Florida, 680N

Pastor-Corrales, M. A., 429N

Pataky, J. K., 633

Paulitz, T. C., 310N, 1021, 1027

Paz Lima, M. L., 573N

Peach

-Botryosphaeria spp., temperature effect on sporulation, 292

-fungicide programs, factors and costs, 162

- sour rot, yeast cause, $222 \mathrm{~N}$

Peach latent mosaic viroid, fruit trees, Tunisia, $1164 \mathrm{~N}$

Peanut

—early leaf spot, tillage, cultivars, and fungicide inputs, 858

-Tomato spotted wilt virus, resistance in transgenic plants, 259

Pear

-Botrytis cinerea, infection timing, 468

-brown spot, field evaluation for maturity, 215

-bull's eye rot, etiology in Oregon,

Washington, and California, 1134

-Phacidiopycnis rot, Washington, 413

- postharvest decay, thiabendazole drench, 474

— postharvest fruit rot, Sphaeropsis cause, 114

Pear blister canker viroid, fruit trees, Tunisia, $1164 \mathrm{~N}$

Pearson, M., 119

Pedersen, W. L., 325

Peever, T. L., 125

Pellegrin, F., 1046N, 1047N

Pelter, G. Q., 222N, 1061

Peltier, A. J., 1033

Peng, G., 605

Penicillium spp., on apple, blue mold in Uruguay, 23

Pennisetum glaucum, tobacco root-lesion nematode management, 989

Penyalver, R., 428N

Pepino mosaic virus, natural hosts, Spain, $906 \mathrm{~N}$

Pepper golden mosaic virus, on tomato, in Mexico, 221N

Pepper mild mottle virus, on green pepper, detection of immunological system, 650

Peres, N. A. R., 125, 731

Pereyra, S. A., 724, 1162N

Pérez, B. A., 1384N 
Pérez, I., $1285 \mathrm{~N}, 1286 \mathrm{~N}$

Periwinkle, Phytophthora blight, control with extracts and oils, 11

Peronospora sp., on basil, in Italy, 312N

$-P$. destructor, on onion, model for prediction, 695

-P. farinosa, on spinach, race 5 in Florida, 84N -P. grisea, on veronica, in Italy, $424 \mathrm{~N}$

$-P$. parasitica, on wild rocket, Italy, $1381 \mathrm{~N}$

- $P$. radii, on marguerite daisy, California, $1163 \mathrm{~N}$

Perrier, X., 1189

Peterschmitt, M., 681N

Petersen, F. P., 572N

Petersen, G. L., 316

Peterson, D. L., 662

Petit, A., 428N

Petunia, root rot, Argentina, $86 \mathrm{~N}$

Pfeiffer, W., 703

Pfender, W. F., 1017

Pfister, S. E., 359

Phacidiopycnis piri, on pear, prevalence in Washington, 413

Phaeomoniella chlamydospora, on grape:

-French American hybrids, Chile, $1285 \mathrm{~N}$

- propagation material for control, 1241

Phakopsora pachyrhizi, on soybean,

epidemiology and risk assessment, 523

Phaseolus vulgaris

-anthracnose, pathotypes in Mexico, 152

—phyllody, phytoplasma cause, $429 \mathrm{~N}$

-rust, phenotypes and genotypes in Americas, 830

-Southern bean mosaic virus, Morocco, $1162 \mathrm{~N}$

-white mold, yield and nonirrigation, 1352

Phatak, S. C., 858

Phellinus wirii, on Sabina przewalskii, in China, $573 \mathrm{~N}$

Phelps, K., 695

Phialophora gregata, on soybean, resistance, 761

Phibbs, A., $1285 \mathrm{~N}$

Phipps, P. M., 683N

Phoma sclerotioides, on alfalfa, in Wisconsin, $769 \mathrm{~N}$

Phomopsis spp.

-P. arnoldiae, on Russian olive, twig canker in Italy, $1048 \mathrm{~N}$

- P. longicolla, on soybean, cultivar and fungicide effect, 721

$-P$. sclerotioides, on cucumber, Italy, $425 \mathrm{~N}$

$-P$. viticola, on grape, cane and leaf spot symptoms, cover photo, September

Phytophthora spp., on soybean, Illinois field traits, 1139

-P. cactorum: mefenoxam resistance, in USA, $576 \mathrm{~N}$; on strawberry, AFLP analysis, inoculum source, 714

-P. capsici: on chile pepper, soil salinity, 205; pumpkin, host range, 485; vegetable crops, management challenges, feature, 1292

-P. cinnamomi, on Ilex glabra, in Virginia, $1283 \mathrm{~N}$

-P. erythroseptica, on potato, mefenoxam control, 301

-P. infestans: on black nightshade, Wales, $771 \mathrm{~N}$; dimethomorph, resistance, 930; on potato, management, Peru, symposium, 565; on potato, resistance in Pacific Northwest, 965; on potato, soilborne oospores, winter fallow, Mexico, 29; on tomato, in Belgium, $86 \mathrm{~N}$

-P. ipomoeae, on Ipomoea purpurea, Mexico, $1283 \mathrm{~N}$

-P. nicotianae: on Skimmia japonica, Italy, $905 \mathrm{~N}$; in soil, population density, extracts and oils, 11

-P. palmivora, on Eustoma grandiflorum, root rot and stem blight, $224 \mathrm{~N}$
-P. ramorum: on Botryosphaeria dothidea, disease progression, 852; ornamental hosts, ericaceous, 993; in ornamental nurseries, Oregon, 87N; on Rosa gymnocarpa, foliar infection, $430 \mathrm{~N}$

-P. sojae, on soybean, races in Arkansas, 345

- $P$. vignae, on Adzuki bean, distribution in Japan, 875

Phytoplasma

- elm yellows, witches'-broom association on paper mulberry, $770 \mathrm{~N}$

-on hop, $908 \mathrm{~N}$

-on Phaseolus vulgaris, phyllody disease, $429 \mathrm{~N}$

- potato purple top, cause in Washington and Oregon, 429N

-rhododendron, Czech Republic, 906N

-on rose in Poland, 1283N

Pianzzola, M. J., 23

Pigeonpea, sterility mosaic, green plague, review, 436

Pigeonpea sterility mosaic virus, leaf symptoms, cover photo, May

Pina, J. A., 906N

Pinckard, T. R., 1255

Pine, loblolly, decline association with Leptographicum spp., pathogenicity, 1174

Pinus spp.

-P. albicaulis, white pine blister rust, Nevada, $772 \mathrm{~N}$

-P. aristata and P. longaeva, white pine blister rust, first report, $311 \mathrm{~N}$

-P. pseudostrobus, dwarf mistletoe, Mexico, $1046 \mathrm{~N}$

Pioli, R. N., 220N, 1044N

Pivonia, S., 523

Plakhine, D., $1284 \mathrm{~N}$

Plasmodiophora brassicae, on Eruca sativa, Brazil, 573N

Plasmopara spp.

-P. helianthi, on sunflower, races 700 and 703 in Italy, $1284 \mathrm{~N}$

-P. obducens, on impatiens: California, 909N, cover photo, August

$-P$. viticola, on grape, resistance in eight clones, 741

Platanus spp., Xylella fastidiosa, temperature and resistance factors, 951

Pleospora allii, on pear, pseudothecia, maturity estimation, 215

Plewa, R., 1381N

Ploetz, R. C., 772N

Plum pox virus, on plum and apricot, Kazakhstan, 973

Podosphaera xanthii, on Cucumis melo, race 2 in Brazil, 1161N

Polizzi, F., 310N

Polizzi, G., 85N, 424N

Polston, J. E., 1160N

Pomerinke, M., 935

Pompeu, J., Jr., 1382N

Poncirus trifoliata, viroid, host, and irrigation interaction, 709

Populus spp., rust, Eastern North America, 85N

-P. alba, Cytospora canker, Israel, $220 \mathrm{~N}$

Porchas, M., 665

Porras, M., 878

Porter, L. D., 965

Pospieszny, H., 1381N

Postharvest pathology

—apple blue mold: biocontrol, 662; Uruguay, 23

—blue mold on apple, Uruguay, 23

-Botrytis cinerea on pear, infection timing, 468

- cranberry fruit rot, causes in Michigan, 1277

- jujube fruit disease, biocontrol with yeast, fungicides, 497

-Monilia and Monilinia spp., stone fruits, multiplex PCR for identification, 1219
- pear decay, thiabendazole, 474

- pear fruit rot, Sphaeropsis cause, 114

-Phacidiopycnis rot in pear, Washington, 413

Postman, J. D., 907N

Potato (see also Solanum)

-black scurf and stem canker, anastomosis grouping in South Africa, $83 \mathrm{~N}$

- common scab, phytotoxicity and severity, 785

- early blight, genetic diversity in South Africa 959

- early dying: author response to Davis and Huisman, 1172; management, letter, 1168

-late blight: dimethomorph resistance, 930; farmer field schools and research, symposium, 565; resistance in Pacific Northwest, 965

- Phytophthora infestans, oospore survival in Mexico, 29

- pink rot and leak tuber, etiology, mefenoxam efficacy, 301

- powdery mildew, California, 309N

- purple top, phytoplasma cause, $429 \mathrm{~N}$

- Sclerotinia stem rot, field development in

Washington, 419

- tuber rots, phosphorous acid application, 1153

-Verticillium wilt, resistance inheritance, diploid hybrids, 1075

Potato mop-top virus, detection in USA and Canada, 363

Potato virus $A$

—on black and hairy nightshade, $905 \mathrm{~N}$

-on Nicotiana megalosiphon, new host, 1160N

Potato virus $V$, nucleic acid characterization, properties, 368

Potato virus $Y$, seedborne, cultivar performance, 248

Potyvirus, on calla lilies, latent infection in Taiwan, $1046 \mathrm{~N}$

Pourrahim, R., 424N, 909N, 1069

Powell, C. A., 625

Powelson, M. L., 1172

Power, A. G., 574N

Prairie, tallgrass species, Barley yellow dwarf, Kansas, 574N

Prakash, O., 575N

Prakash, S., 426N, 906N

Pratylenchus penetrans, on tobacco, pearl millet for management, Quebec, 989

Protection, agriculture, regulatory action, legal basis in Florida, 1040

Pryor, B. A., 776

Pryor, B. M., 426N

Pseudomonas spp.

-P. cichorii, on Borago, Spain, 769N

-P. savastanoi, on olive, copper sprays, factors, 131

-P. syringae: on arugula, California, $1384 \mathrm{~N}$; biocontrol agent, apple blue mold, 662; on cauliflower, leaf spot, cover photo, July; on tomato, outbreak in Turkey, $1050 \mathrm{~N}$

-P. viridiflava, on watermelon, Turkey, $907 \mathrm{~N}$

Pseudotsuga menziesii, itch canker, in California, $772 \mathrm{~N}$

Puccinia spp.

-P. allii, on Allium spp., first rust report, $83 \mathrm{~N}$

$-P$. graminis, on ryegrass, planting date and age effect, 1017

-P. helianthi, on sunflower, fungicides, 657

$-P$. hemerocallidis, on daylily, fungicides for, 657

-P. pelargonii-zonalis, on geranium, fungicides, 657

-P. striiformis, on wheat, epidemic in China, 896

-P. tritici: on durum wheat, Mexico, 703; on hard red spring wheat, resistance characterization, 1127; on wheat, adult plant resistance, genes, 1107; on wheat, races in USA, in 2002, 1079; on wheat, virulence 
diversity pattern, Egypt and USA, 271; on winter wheat, resistance genes, 136

Pumpkin

-Beet pseudo yellows virus, in California, $82 \mathrm{~N}$

-Phytophthora blight, host range, 485

Pun, K. B., 428N

Punja, Z. K., 427N

Putnam, M. L., 222N, 574N

Pyracantha coccinea, fire blight, Bulgaria, $427 \mathrm{~N}$

Pyrenophora spp.

- P. teres, on barley, Uruguay, first report, $1162 \mathrm{~N}$

-P. tritici-repentis, on rice-wheat system in Asia, symposium, 552

Pyricularia spp.

-P. grisea, on ryegrass, ethofumesate application, timing, 1146

-P. setariae, on green foxtail, moisture and temperature effect, 605

Pythium spp.: propamocarb and mefenoxam resistance, greenhouses, 630; on wheat, adapted cultivar evaluation, 1027; on wheat, virulence in Washington, 1021

$-P$. irregulare, on lentil, $310 \mathrm{~N}$

-P. splendens, on Pachira aquatica, first report, $84 \mathrm{~N}$

-P. tracheiphilum, on lettuce, wilt and leaf blight in Spain, 1382N

-P. ultimum, on potato, mefenoxam control, 301

Quercus velutina, leaf scorch, first report in

Washington, D.C., 224N

Quezado-Duval, A. M., 157

Quiñones, M., 572N

Rabenstein, F., 453

Radišek, S., 1115

Radish, common scab, isolates and disease severity, 785

Radish mosaic virus, on cauliflower and turnip, Iran, 909N

Raetz, E., 1255

Rahimian, H., 683N

Raid, R. N., 84N

Raikhy, G., 86N, 1161N

Rajcan, I., 891

Rakhshandehro, F., 424N

Ralstonia solanacearum, on tomato, management with rhizobacteria and fungicide, 669

Ram, R., 86N, 1161N

Ramis, C., $681 \mathrm{~N}$

Ramos, A., 428N

Ramularia sphaeroidea, on purple and lana woollypod vetch:

-in California, 221N

-leaf spot, cover photo, February

Rangel, S., 516

Rawnsley, B., 1005

Raynal, G., 1213

Regulation, protecting agriculture, legal basis in Florida, 1040

Remah, A., 1162N

Resistance

-banana to Fusarium wilt, somaclonal variation, 580

—barley to Fusarium head blight, 167

- cacao to witches'-broom, 797

- canola to Sclerotinia stem rot, inoculation technique, 1033

- citrus to canker: induced, 745; triploid hybrids, 1056

- cucumber to Phytophthora leaf blight and Trichoderma hamatum, 280

-Eucalyptus to Ceratocystis fimbriata, 758

- grape to downy mildew, eight clones, 741
- payaya to Papaya ringspot virus, transgenic, 352,516

- peanut to: early leaf spot, 858; Tomato spotted wilt virus, transgenic, 259

— potato to: late blight, Pacific Northwest, 965 Verticillium wilt, interspecific hybrids, 1075

-race-specific genes, computer program, 545

- soybean to cyst nematode, North Carolina, 942

-sunflower to broomrape, 479

-wheat to: leaf rust, hard red spring, characterization, 1127 ; leaf rust, new race in Mexico, 703; leaf rust, soft red winter, genes, 1107; Stagonospora nodorum leaf blotch, inheritance, 530

-winter wheat to leaf rust, seedling genes, 136

Reuther, K. D., 430N

Reviewers, acknowledgment, 88

Reynaud, B., 681N

Rhizoctonia solani

—on corn, AG-13 hybrid, Mississippi, 908N

-on petunia, Argentina, $86 \mathrm{~N}$

-on potato, anastomosis grouping in South Africa, $83 \mathrm{~N}$

-soybean, anastomosis groups, survival, 817

Rhododendron, phytoplasma, Czech Republic, $906 \mathrm{~N}$

Rhodotorula glutinis, biocontrol agent for Botrytis on geranium, 1262

Ribes spp., white pine blister rust, Nevada, $772 \mathrm{~N}$

Rice

-blast, avirulence and resistance genes, identification, 265

-leaf and neck blast, silicon and fungicides, 253

—red stripe: causal agent, 1310; histopathology, 1304

- sheath blight, management with antagonistic bacteria, symposium, 557

Richardson, P. A., 1283N

Ricke, G., $1286 \mathrm{~N}$

Ricker, M. D., 228

Riley, D.G., $1285 \mathrm{~N}$

Rimmer, S. R., 4, 308

Rivera, M. C., $86 \mathrm{~N}, 1160 \mathrm{~N}, 1164 \mathrm{~N}, 1384 \mathrm{~N}$, $1383 \mathrm{~N}$

Rivera-Bustamante, R. F., $221 \mathrm{~N}$

Rizzo, D. M., 852

Rochon, D., 1092

Rodríguez-Alvarado, G., 1283N

Rodríguez Codazzi, A., 1383N

Rodríguez Guerra, R., 152

Rogers, J. D., 114, 223N

Roh, J.-H., 64

Roloff, I., 397

Rolshausen, P. E., 925

Román, M. P., 453

Romberg, M. K., 309N

Romero, F., 878

Romero, J., 1049N

Rosa gymnocarpa, Phytophthora ramorum on, foliar infection, $430 \mathrm{~N}$

Rosales, I. M., 935,1286N

Rose

- phytoplasma from apple proliferation group, Poland, $1283 \mathrm{~N}$

- Strawberry latent ringspot virus, in India, $86 \mathrm{~N}$

Rosenberger, D. A., 869

Rossi, M. L., 573N

Rossman, A. Y., 222N, 427N, 1161N

Rotylenchulus reniformis, on cotton, Virginia, $683 \mathrm{~N}$

Rouse, D. I., 1075

Rowe, R. C., 1172

Ruberti, D., 1044N

Ruellia brittoniana, southern blight, Louisiana, $770 \mathrm{~N}$
Rundell, P. A., 625

Rupe, J. C., 345

Russin, J. S., 613, 620

Sabina przewalskii, root rot, in China, 573N

Saenz, G. S., 1163N

Sahin, F., 310N, 907N

Salas, B., 301

Salcedo, C. I., 428N

Sales, R., Jr., $84 \mathrm{~N}$

Salih, S., 1347

Salix spp.

- S. bebbiana, rose gall, leaf infection, cover photo, January

-S. lucida, Septoria leaf spot, new host, $770 \mathrm{~N}$

Salvia spp.

-S. officinalis, white mold, Italy, 1044N

-S. scabra, powdery mildew, Italy, $682 \mathrm{~N}$

Sánchez, J. J., 428N

Sanitation, substrate, Botrytis cinerea, disinfestants, 509

Sanogo, S., 205, 1049N

Santiago, J. L., 741

Santos, P., 909N

Sato, D. M., 1318

Saunders, J. A., 1269

Savard, M., 837

Sawyer, T. L., 41

Saxena, K. B., 436

Saygili, H., 907N

Scandiani, M., 1044N

Scherm, H., 397

Schilder, A. M. C., 1277

Schloemann, S., $572 \mathrm{~N}$

Schnabel, G., 162, 576N, 714, 1000

Schneider, R. W., 613, 620

Schubert, T. S., 1179

Schuta, L. R., 573N

Sclerotinia spp., on lettuce, fungicides for, 665

-S. homoeocarpa: on Agrostis stolonifera, Argentina, $1384 \mathrm{~N}$; on turfgrass, genetic diversity in North America, 1269

- S. minor, on geranium, stem and leaf blight, North Carolina, $312 \mathrm{~N}$

-S. sclerotiorum: on Brassica napus, resistance evaluation and inoculation technique, 1033; on common sage, Italy, $1044 \mathrm{~N}$; on dry bean, yield under nonirrigation, 1352; on dry bean, white mold, cover photo, December; on Felicia amelloides, in Italy, $575 \mathrm{~N}$; on Hutchinsia alpina, white mold, Italy, 1045N; mycelial compatibility grouping, 325 ; on petunia, white mold, cover photo, April; on potato, field development in Washington, 419; on soybean, genetics, straw inoculation method, 891; on soybean, yield and growth stages, 297; on Thymus $\times$ citriodorus, Italy, $1044 \mathrm{~N}$

Sclerotium spp.

-S. cepivorum, on onion, inoculum density and suppression by Trichoderma, 287

-S. rolfsii: on chickweed, North Carolina, 426N; on Jerusalem artichoke, California, $769 \mathrm{~N}$; on laurustinus, cover photo, March; on Ruellia brittoniana, Louisiana, 770N; on Viburnum tinus, first report, $310 \mathrm{~N}$

Scott, E. S., 1005

Secor, G. A., 429N

Sediva, J., 906N

Seebold, K. W., Jr., 253

Seem, R. C., 869

Segev, L., $1160 \mathrm{~N}$

Segundo, E., 1162N

Seifers, D. L., 824

Semancik, J. S., 709

Septoria spp.

- S. albopunctata, on blueberry, photosynthesis and leaf damage, 397

-S. linicola, on flax, fungicides and cultivars 
for management, 1123

-S. musiva, on shining willow, new host, $770 \mathrm{~N}$

-S. pistacearum, on pistachio, leaf spot, cover photo, April

Sepúlveda, P., 1286N

Setaria viridis, fungi as bioherbicides for, 605

Shahraeen, N., 1069

Shannon, J. G., 721

Sharma, J., $221 \mathrm{~N}$

Shaw, D. S., 771N

She, Y.-M., 824

Shen, Q., 837

Shepherd, L. M., 633

Sherwood, J. L., $1285 \mathrm{~N}$

Shew, B. B., 312N, 426N

Shiel, P. J., 368

Shih, S. L., 311N

Shimada, H., 875

Shimizu, T., 865

Shintaku, M. H., 1318

Shishkoff, N., 425N

Silphium laciniatum, stem blight, Poland, $1045 \mathrm{~N}$

Silva, J. F., 758

Sim, T., 316

Simoneau, P., 490

Simpson, J., 152

Sims, A. L., 724

Singh, A. K., 1161N

Singh, B. P., 575N

Singh, L., 1161N

Singh, R. P., 703

Sirca, S., 680N

Sirococcus clavigignenti-juglandacearum, conidial viability, on beetles, 1085

Skaracis, G. N., 645

Skimmia japonica, Phytophthora nicotianae on, Italy, $905 \mathrm{~N}$

Slack, S. A., 368

Sleper, D. A., 721

Slippers, B., 959

Sliwa, H., 908N, 1283N

Smith, A., 430N

Smith, B. J., 195

Smith, J. P., 576N

Smith, R. F., 221N

Snyder, G. H., 253

Sohn, S.-I., 641

Soika, M. D., 1146

Soil, salinity, chile pepper infection response, 205

Soil disinfestation, biological, mulch, for Verticillium dahliae, 688

Solanum spp. (see also Potato): Potato virus A, weed hosts, $905 \mathrm{~N}$

-S. nigrum, Phytophthora infestans, in Wales, $771 \mathrm{~N}$

Solarska, E., 908N

Solel, Z., 220N

Sookmark, U., 1047N

Southern bean mosaic virus, on French bean, Morocco, 1162N

Souza, N. L., 125, 731

Soybean

-brown stem rot, cyst nematode resistance relation, 761

- cyst nematode: North Dakota, 1287N; resistant populations, North Carolina, 942

-Fusarium graminearum, pathogenic, $220 \mathrm{~N}$

-Phomopsis seed decay, cultivar and fungicide effect, 721

-Phytophthora root and stem rot, races in Arkansas, 345

-Phytophthora spp., populations in Illinois fields, 1139

-red crown rot: factors, 613; soil temperature effect, 620

-Rhizoctonia solani, anastomosis groups, temperature, 817 —rust, epidemiology and risk assessment, 523

-Sclerotinia sclerotiorum, mycelial compatibility grouping, 325

-Sclerotinia stem rot: genetics, straw inoculation method, 891; yield effect, growth stages, 297

- stem canker, in Wisconsin, $576 \mathrm{~N}$

-sudden death syndrome: Argentina, 1044N; detection with PCR, 1372; root factors, 1011

- viruses, in Iran, 1069

Soybean dwarf virus, Wisconsin, $1285 \mathrm{~N}$

Soybean mosaic virus, strain identification, cylindrical inclusion coding region, identification, 641

Sparks, A. N., $1285 \mathrm{~N}$

Sparry, E., 837

Sphaeropsis pyriputrescens

—on apple, postharvest fruit rot, $223 \mathrm{~N}$

-on pear: postharvest fruit rot, 114; stem-end rot, cover photo, February

Sphaerotheca macularis, on strawberry, airborne conidia, 878

Spiegel, S., 973

Spinach, downy mildew, race 5 in Florida, 84N

Spiraea japonica, powdery mildew, in Italy, $1045 \mathrm{~N}$

Spotts, R. A., 474, 1134

Stagonopora nodorum, on wheat, resistance inheritance, 530

Stall, R. E., 1179

Standing, K. G., 824

Starr, J. L., 100

Stavisky, J., 882

Steadman, J. R., 830

Stein, J. M., 930

Stellaria media, Sclerotium rolfsi, North Carolina, $426 \mathrm{~N}$

Stenotaphrum secundatum, gray leaf spot, silicon and chlorothalonil effect, 338

Stensvand, A., 869

Stevens, W. E., 721

Stevenson, K.L., 858, 951

Stewart, J. E., 1085

Stockwell, V. O., 41

Stone fruit, Monilinia fructicola, fungicide sensitivity, 373

Stover, P., $772 \mathrm{~N}$

Stravato, V. M., $425 \mathrm{~N}$

Strawberry

—anthracnose: pathogenicity, 407; screening method, 845

-methyl bromide, alternatives in nurseries, 210

-pallidosis, virus association, 383

- Phytophthora cactorum, AFLP analysis, inoculum source, 714

- powdery mildew, airborne conidia, 878

Strawberry latent ringspot virus

—on Mentha sp., first in North America, 907N

-on rose, in India, $86 \mathrm{~N}$

-in USA and Canada, $575 \mathrm{~N}$

Streptomyces spp.: on radish, isolates, variation, 785 ; on turnip, phytotoxin-producing strain, $680 \mathrm{~N}$

- S. acidiscabies, on radish, lesions, cover photo, August

Strieth, L., $1382 \mathrm{~N}$

Stromberg, V. K., 1179

Subbarao, K. V., 49

Sugar beet, powdery mildew, perfect stage in Nebraska, 1049N

Sugar, D., 1134

Sullivan, K. F., 311N

Summer, B. E., 1005

Sun, X., 1179

Sunflower, broomrape:

- cultivar response, 479

-new race in Israel, $1284 \mathrm{~N}$

Surujdeo-Maharaj, S., 797

Sutton, B. D., 1179
Sutton, T. B., 1335

Suzuki, H., 84N

Suzuki, O., $1161 \mathrm{~N}$

Swain, S., 430N

Swart, W. J., 333, 1284N

Sweet cherry, Little cherry virus, high sequence variability, British Columbia, 1092

Sweet potato chlorotic stunt virus, on sweetpotato, Spain, $428 \mathrm{~N}$

Sweet potato feathery mottle virus, on sweetpotato, Spain, $428 \mathrm{~N}$

Sweetpotato

- geminiviruses, PCR for detection, 1347

- viruses, Tanzania, 916

Syncephalastrum racemosum, on Indian gooseberry, black soft rot, $575 \mathrm{~N}$

Tairo, F., 916

Takita, M. A., $1382 \mathrm{~N}$

Tanaka, F. A. O., 453

Tardif, M.-C., 1219

Targon, M. L. P. N., 1382N

Taylor, R. J., 301

Teifion Jones, A., 436

Teixeira, D. C., 453

Tekauz, A., 167

Tello Marquina, J. C., 1383N, 1382N

Termorshuizen, A. J., 688

Teviotdale, B. L., 131

Theilmann, J., 1092

Thekopsora minima, urediniospores and uredinia, temperature effect, 359

Theobroma cacao, witches'-broom, resistance, 797

Thielaviopsis basicola, chlorine dioxide effect, 188

Thies, J. A., 589

Thomas, P. E., $905 \mathrm{~N}, 1160 \mathrm{~N}$

Thomma, B. P. H. J., $86 \mathrm{~N}$

Thompson, K. C., 545

Thornton, M. K., 248

Thrips tabaci, Iris yellow spot virus vector, Colorado, 446

Thurston, H. D., 550

Thymus $\times$ citriodorus, white mold, Italy, 1044N

Tian, D., 485

Tian, G. Z., 683N

Tilletia indica

-teliospores, survival in soil, 56, 316

-wheat, teliospore survival, Arizona soil, 804

Timmer, L. W., 125, 379, 731

Tisserat, N. A., 1341

Tjosvold, S. A., 1163N

Tobacco (see also Nicotiana spp.): root-lesion nematode, pearl millet for management, 989

Tobacco mild green mosaic virus, on tobacco, color-break, cover photo, July

Tobacco mosaic virus

-Canavalia ensiformis, in Venezuela, 681N

-on hibiscus, detection method, 34

Tojo, M., 84N

Tomaso-Peterson, M., $908 \mathrm{~N}$

Tomato

-bacterial canker: greenhouse, in Turkey, $1048 \mathrm{~N}$; seed infection, Indonesia, 680N

-bacterial speck, outbreak in Turkey, 1050N

-bacterial spot: management by bactiophages and SAR inducers, 736; outbreaks in Brazil, 157; in Turkey, $85 \mathrm{~N}$

-bacterial wilt, integrated management, bacteria in fungicides, 669

-Pepper golden mosaic virus, Mexico, 221N

-root and foot rot, in Belgium, $86 \mathrm{~N}$

-root-knot nematode, Slovenia, 680N

Tomato chlorosis virus

- hosts in Spain, 82N

-in Israel, first report, $1160 \mathrm{~N}$

-on sweet pepper, natural host, $224 \mathrm{~N}$

-in Taiwan, $311 \mathrm{~N}$ 
Tomato infectious chlorosis virus

-hosts in Spain, 82N

-in Taiwan, $311 \mathrm{~N}$

Tomato leaf curl virus, in Mayotte, new, $681 \mathrm{~N}$

Tomato mosaic virus, on Hibiscus, China, $683 \mathrm{~N}$

Tomato spotted wilt virus

—on Allium cepa, Georgia, $1285 \mathrm{~N}$

-management in field, 882

-on peanut: cover photo, March; transgenic, resistance, 259

Tomato yellow leaf curl virus, on squash, in Cuba, 572N

Tomer, S. P. S., 426N, 906N

Tooley, P. W., 993

Toppe, B., 224N

Torés, J. A., $905 \mathrm{~N}$

Torrance, R. L., 1285N

Torres, H., $1162 \mathrm{~N}$

Tosi, L., 425N, 1284N

Toxoptera citricida, Citrus tristeza virus vector, distribution in Florida, 935

Trevathan, L. E., 908N

Trichoderma hamatum, biocontrol, Phytophthora crown rot and leaf blight of cucumber, resistance, 280

Trouillas, F., 925

Trouslot, P., $1047 \mathrm{~N}$

Truffi, D., 157

Truniger, V., $907 \mathrm{~N}$

Truter, M., $82 \mathrm{~N}$

Tsai, H. T., $1046 \mathrm{~N}$

Tsai, W. S., $311 \mathrm{~N}$

Tse, J. G., 430N

Tsuda, S., 650

Tsuga spp., rust, temperature effect on spores, 359

Turechek, W. W., 537

Turfgrass (see also Lolium perenne)

- anthracnose, genetic variation of pathogen, isozyme analysis, 402

- dollar spot, genetic diversity in North America, 1269

-fungicides, application runoff, 391

-root-knot nematode, Israel, 309N

Turnip, scab, phytotoxin, 680N

Tzanetakis, I. E., 223N, 383, 575N, 907N

Uddin, W., 1146, 1269

Umaharan, P., 797

Umesh, K. C., 1226

Uncinula spp.

-U. necator: on grape, trifloxystrobin and spiroxamine effect, California, 1205;

perennation, Washington vineyards, 242

-U. tulasnei, on Norway maple, symptoms, cover photo, September

Urek, G., 680N

Uromyces spp.

-U. appendiculatus, on Phaseolus vulgaris, phenotypes and genotypes in the Americas, 830

Vaccinium corymbosum, Alternaria leaf spot, twig blight, fruit rot, Argentina, 1383N

Vakalounakis, D. J., 645

Valdés, F., 428N

Valerianella olitoria, Fusarium. vascular wilt, in Italy, $83 \mathrm{~N}$

Valkonen, J. P. T., 916

Valova, P., $906 \mathrm{~N}$

Valverde, R. A., $428 \mathrm{~N}$

Vanachter, A. C. R. C., $86 \mathrm{~N}$

van Bruggen, A. H. C., 688

Vanc, P., 906N

Vandemark, G. J., 769N

van der Waals, J. E., 959

van der Wolf, J. M., $680 \mathrm{~N}$

van der Zouwen, P. S., 680N

van Iersel, M. W., 397
Vanilla tahitensis, viruses, symptoms in French Polynesia, 119

Varga, A., 973

Vargas, J. M., Jr., 402

Varma, A., 221N, 428N

Vázquez Juárez, R., 221N

Venette, J. R., 1352

Venturia inaequalis

-on apple: conidial overwintering, scab epidemic, 751; fungicide resistance, 537

-ascospores, maturity and release, method comparison, 869

Verbena, Bean yellow mosaic virus, pea mosaic strain, 574N

Verbena canadensis, Clover yellow mosaic virus, in Florida, $223 \mathrm{~N}$

Verma, N., 1161N

Verma, R., 426N, 906N

Vernière, C., 1189

Vero, S., 23

Verticillium spp.

-V. albo-atrum: on alfalfa, forage quality and yield, fungicides and factors, 811; on hop, detection markers, 1115

-V. dahliae: biological soil disinfestation, longterm effect, 688; on potato, resistance inheritance, diploid hybrids, 1075; in soil, recovery media, 49

Viburnum tinus

—powdery mildew, California, $425 \mathrm{~N}$

-southern blight, first report, $310 \mathrm{~N}$

Vicent, A., 84N

Vicia spp., leaf and stem spot, California, 221N

- V. villosa, Fusarium wilt of watermelon suppressed by, amendment, 1357

Vidalakis, G., 709

Vigna angularis, Phytophthora vignae, distribution in Japan, 875

Viji, G., 1269

Vikalakis, G., 1328

Vilchez, M., 909N

Viloria, Z., 1056

Vincelli, P., 391

Vinnere, O., $572 \mathrm{~N}$

Viola $\times$ wittrockiana, Botrytis cinerea, flower infection, Buenos Aires, 1164N

Violett, P., 772N

Viroid, on citrus, growth and yield affected by graft, 1189

Viruses

- geminiviruses, sweetpotato, PCR for detection, 1347

- soybean, occurrence in Iran, 1069

-sweetpotato, in Tanzania, 916

Vitale, A., $85 \mathrm{~N}, 310 \mathrm{~N}, 424 \mathrm{~N}$

Vives, M. C., 906N

Vogler, D. R., 772N

Voldeng, H., 837

Vossbrinck, C., $1287 \mathrm{~N}$

Wagner, A., 1045N

Waliyar, F., 436

Walker, N. R., 100

Walnut (see also Juglans regia): bacterial canker, in France, 220N

Wamishe, Y. A., 545, 1107

Wan, A., 896

Wang, B., 896

Wang, I. T., $1383 \mathrm{~N}$

Wang, Z., 645

Wanishe, Y. A., 136

Wanner, L. A., 785

Watermelon

-Fusarium wilt, soil amendment for suppression, 1357

- Pseudomonas viridiflava, new host in Turkey, $907 \mathrm{~N}$

Watermelon mosaic virus, on vanilla, in French Polynesia, 119
Webster, T. M., 771N

Weeks, J. R., 259

Wegener, L. A., 427N

Wegulo, S. N., 909N

Wehner, F. C., 82N

Were, H. K., 17

Wetzel, H. C., III, 1341

Wharam, C. M., 181

Wheat

- Barley yellow striate mosaic virus, in Syria, $83 \mathrm{~N}$

-Fusarium head blight: choline, betaine, and floral extract effects, 175; inoculum survival in residue, 724

- Karnal bunt, teliospore survival: in Arizona soil, 804 ; in soil, 56, 316

-leaf rust: adult plant resistance, genes, 1107; in Mexico, 703; races in USA, in 2002, 1079; resistance characterization, 1127; seedling resistance genes, 136; virulence diversity in Egypt and USA, 271

-Pythium root rot, cultivar evaluation, 1027

-rice-wheat system, foliar blights in Asia, symposium, 552

- root rot, virulence of Pythium, Washington, 1021

- Stagonospora nodorum leaf blotch, resistance inheritance, 530

—stripe rust, epidemic in China, 896

White, D. G., 633

White, J. F., 63

Whitten, K. R., 1384N

Whitworth, J., 248

Wicks, T. J., 1005

Wierzbicki, R., 1161N

Wilcox, W. F., 869

Wilson, C. R., 287

Winter, S., 17

Wintermantel, W. M., 82N, 1160N

Wrather, J. A., 100, 721

Wright, E. R., $86 \mathrm{~N}, 1384 \mathrm{~N}, 1383 \mathrm{~N}$

Wu, T., $770 \mathrm{~N}$

Xanthomonas spp.

-X. axonopodis: aroid hosts, detection methods, 980; on citrus, lesions, cover photo, October; on citrus, new strain from lime and alemow, Florida, 1179; on citrus, resistance screening, triploid hybrids, 1056; on citrus, systemic resistance compounds, 745; on tomato and pepper, in Turkey, $85 \mathrm{~N}$

-X. campestris: on carrot, PCR-based assay, 1226; on coriander, Taiwan, $910 \mathrm{~N}$; on pepper, copper tolerance, Australian populations, 921; on tomato, management by bacteriophages and SAR inducers, 736

-X. exopodis, on citrus, canker symptoms, cover photo, November

-X. gardneri, on tomato, outbreaks in Brazil, 157

Xiangmin, L., 557

Xiao, C. L., 114, 223N, 413

$\mathrm{Xu}, \mathrm{H} ., 363$

Xylella fastidiosa

-on black oak, Washington, D.C., 224N

-on grape, other hosts in California, 1255

-on grape and oleander, detection technique, 600

-on oleander, leaf scorch in Texas, 1049N

- on sycamore, temperature and resistance factors, 951

Yaegashi, H., 265

Yamamoto, P. T., 453

Yang, H., 259

Yang, Jiaxiu, 896

Yang, Jiu-Sherng, 594

Yang, X. B., 523, 817

Yao, G., 896

Yarden, O., 845 
Yasuda, N., 265

Yeh, S.-D., 594

Yilmaz, S., 1050N

Ying, Z., 352

Yoshimura, M. A., 373

Yu, T.-A., 594

Yuan, Z., 896

Zaidi, A. A., 86N, 1161N
Zantedeschida spp., potyvirus, Taiwan, 1046N

Zauza, E. A. V., 758

Zazzerini, A., $1284 \mathrm{~N}$

Zee, F. T., 1318

Zhang, L., 379

Zhao, J., 1033

Zhao, Y., 770N

Zhao, Z., 896

Zheng, L., 1048N
Zhiyi, C., 557

Zhou, X. G., 1357

Zingiber officinale, rhizome rot, in Hawaii, 1318

Zizyphus jujuba, postharvest diseases,

biocontrol with yeast, fungicides, 497

Zucchini yellow mosaic virus

- on cucumber, in India, $906 \mathrm{~N}$

- on Lagenaria siceraria, India, $426 \mathrm{~N}$

Zveibil, A., 845 